\title{
ON THE CUSP OF A REVOLUTION
}

In geoscience; we run the risk of unfulfilled potential in the world of big data analytics. Mike Stephenson and colleagues suggest the Deep Time Digital Earth project could help by providing a global: data platform, or 'geological Google'.

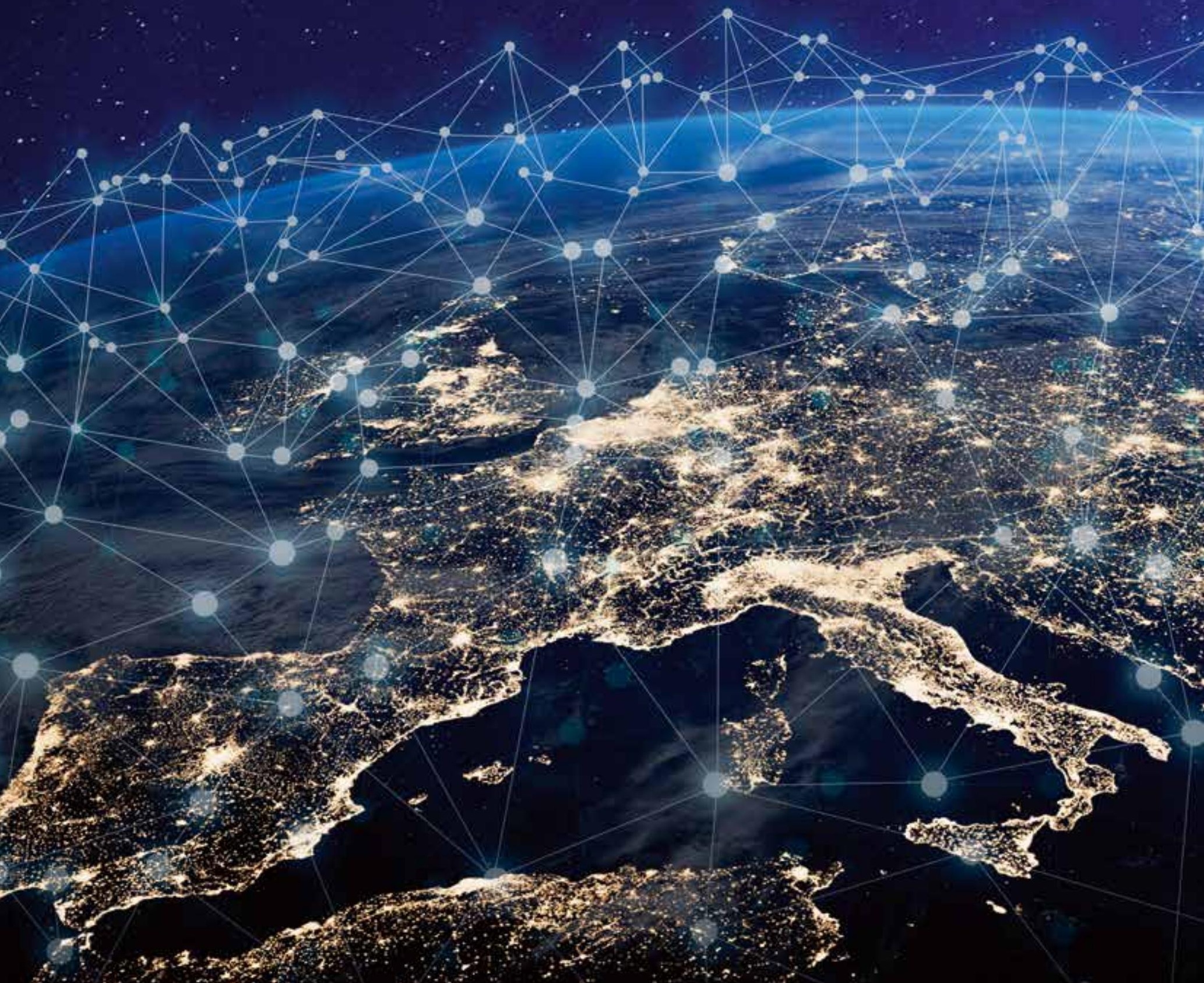


may provide novel glimpses into Earth's geological past and future.

Linking databases will be a big part of DDE. An example is the integration of deep-time data for mapping clusters of porphyry copper mineral deposits (PCDs). It's thought that deep-time plate motion, as well as crustal and slab subduction help control the distribution of PCDs. Some of these processes are described in established databases and models, for example, in relation to crustal thickness in the Crust 1.0 Model, the Global Plate Reconstruction Model, the Slab 2.0 Model and the global U-Pb database. Coupling between these models and databases is possible, but it takes a long time and significant computing skills. The aim of DDE will be to do the hard work in advance, by linking georeferenced databases and models of this type together so that they can be used more efficiently. Data will still reside with the originating institution or individual, so ownership will not change-it's just that the links between databases and models will be better (Fig. 2).
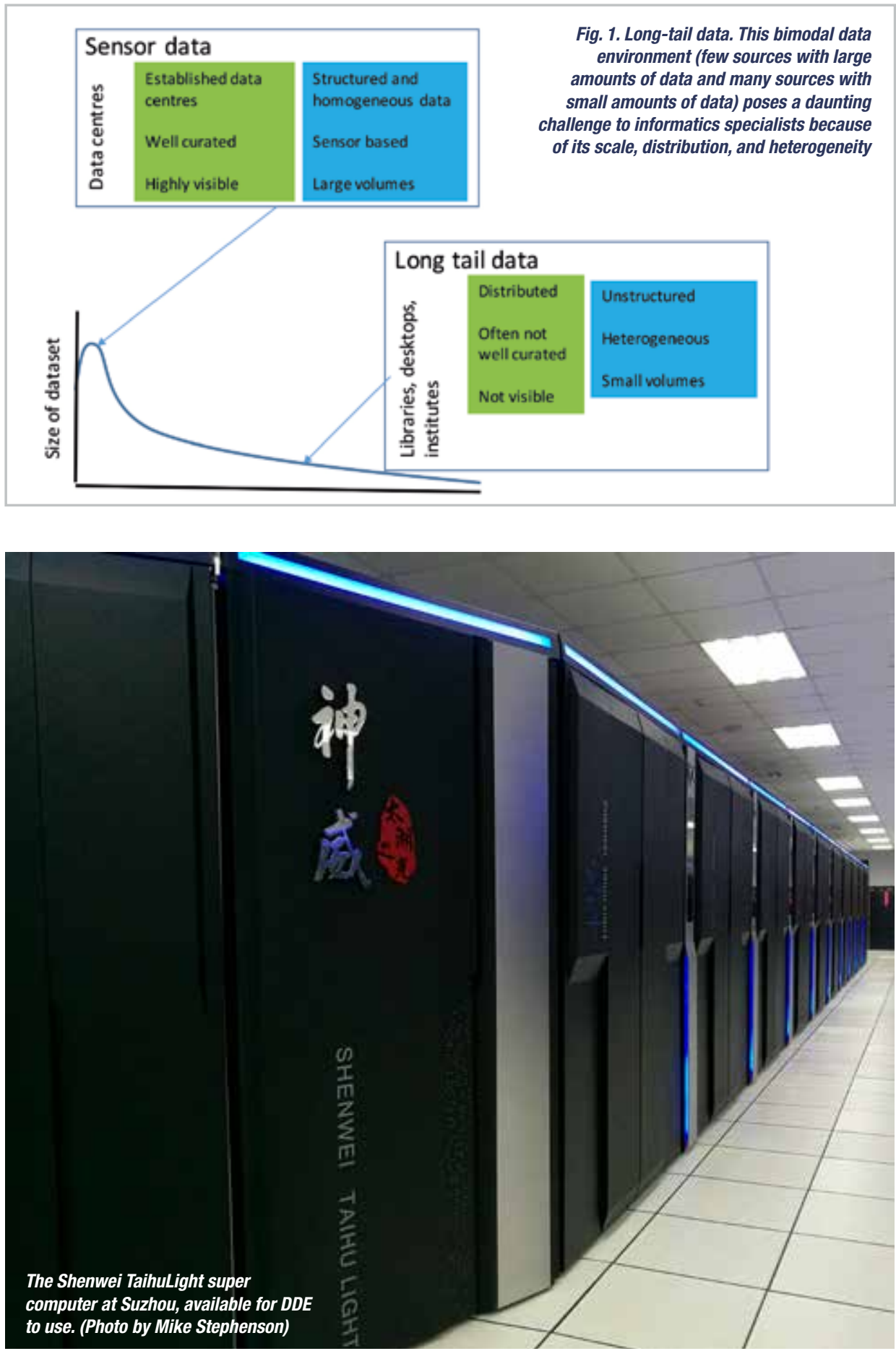

Another example of how DDE will work concerns the evolutionary history of the biosphere. Previous analyses of long-term palaeobiodiversity change were mostly at a resolution of about 10 million years, which is too coarse to reveal the fine details of any changes. Databases linked through DDE could provide high-resolution (10 to 100 thousand year) diversity patterns.

Yet other DDE linkages will aim to address the sustainable development goals. For example, databases and models could be coupled to provide better understanding of African groundwater storage, thereby helping countries vulnerable to climate change.

\section{Vision of the IUGS}

The DDE is closely consistent with the vision of the IUGS, which is to promote development of the Earth sciences through the support of broad-based scientific studies relevant to the entire Earth system.

DDE is a truly global initiative. It brings together a unique range of founding members including the International Commission on Stratigraphy, the International Palaeontological Association, the International Association of

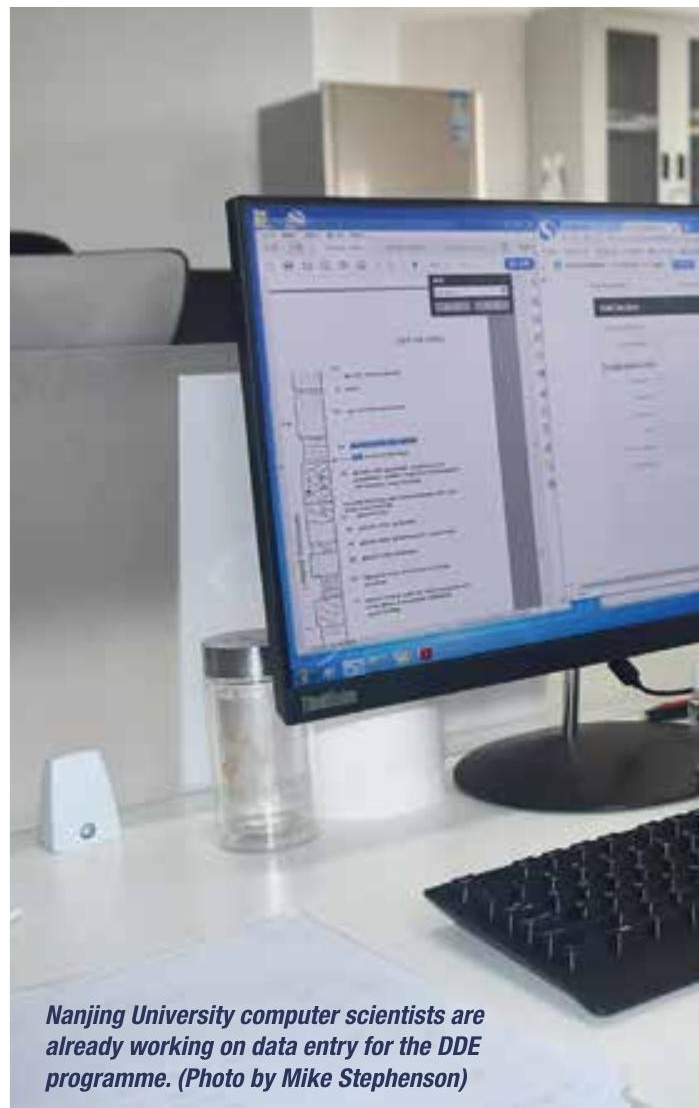


Sedimentologists, the Society for Sedimentary Geology, the American Association of Petroleum Geologists, and the International Association for Mathematical Geosciences. Major geological surveys, institutes and commissions are also involved, including the China Geological Survey, the British Geological Survey, the All Russian Geological Institute, the Commission for Geological Map of the World and the Commission on the
Management and Application of Geoscience Information.

DDE will operate under the full Findable, Accessible, Interoperable, and Re-usable (FAIR) data concept. It will link to the desktop systems of geoscientists all over the world, as well as to students and teachers in classrooms and on the internet. These institutions are coming together at a time when informatics and computing are evolving fast, but where a wider

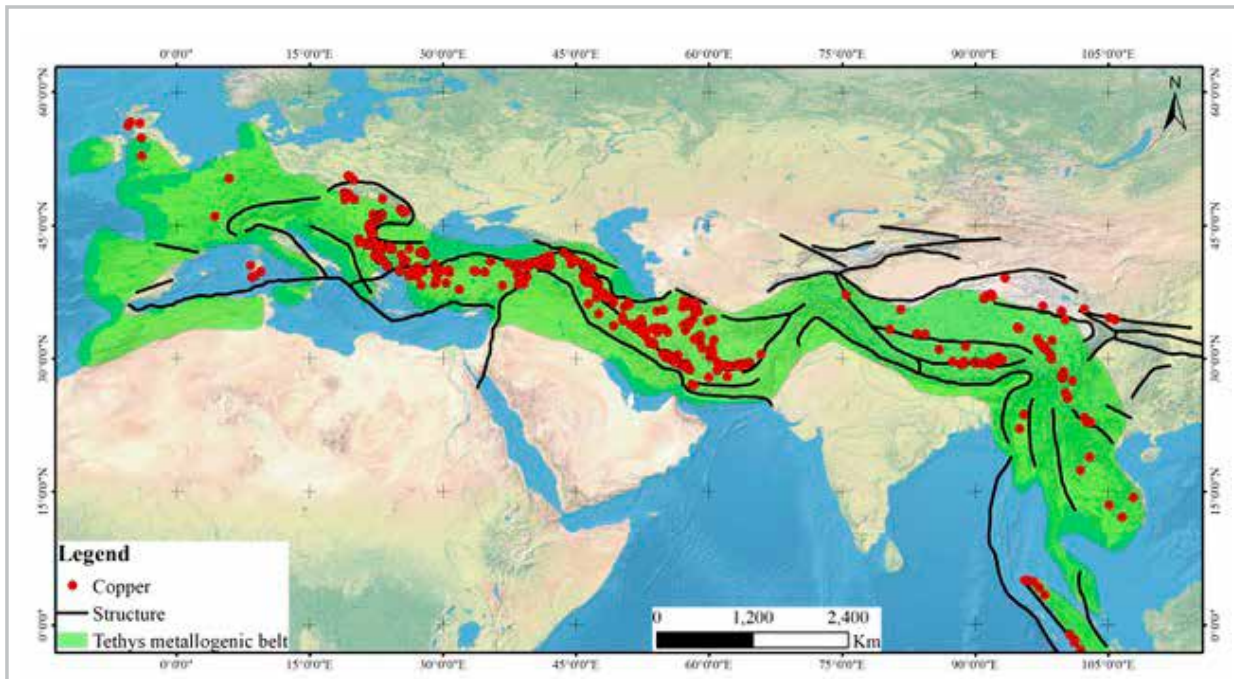

Fig. 2. DDE will link georeferenced databases and models together so that they can be used more efficiently, for example in the study of porphyry copper mineral deposits

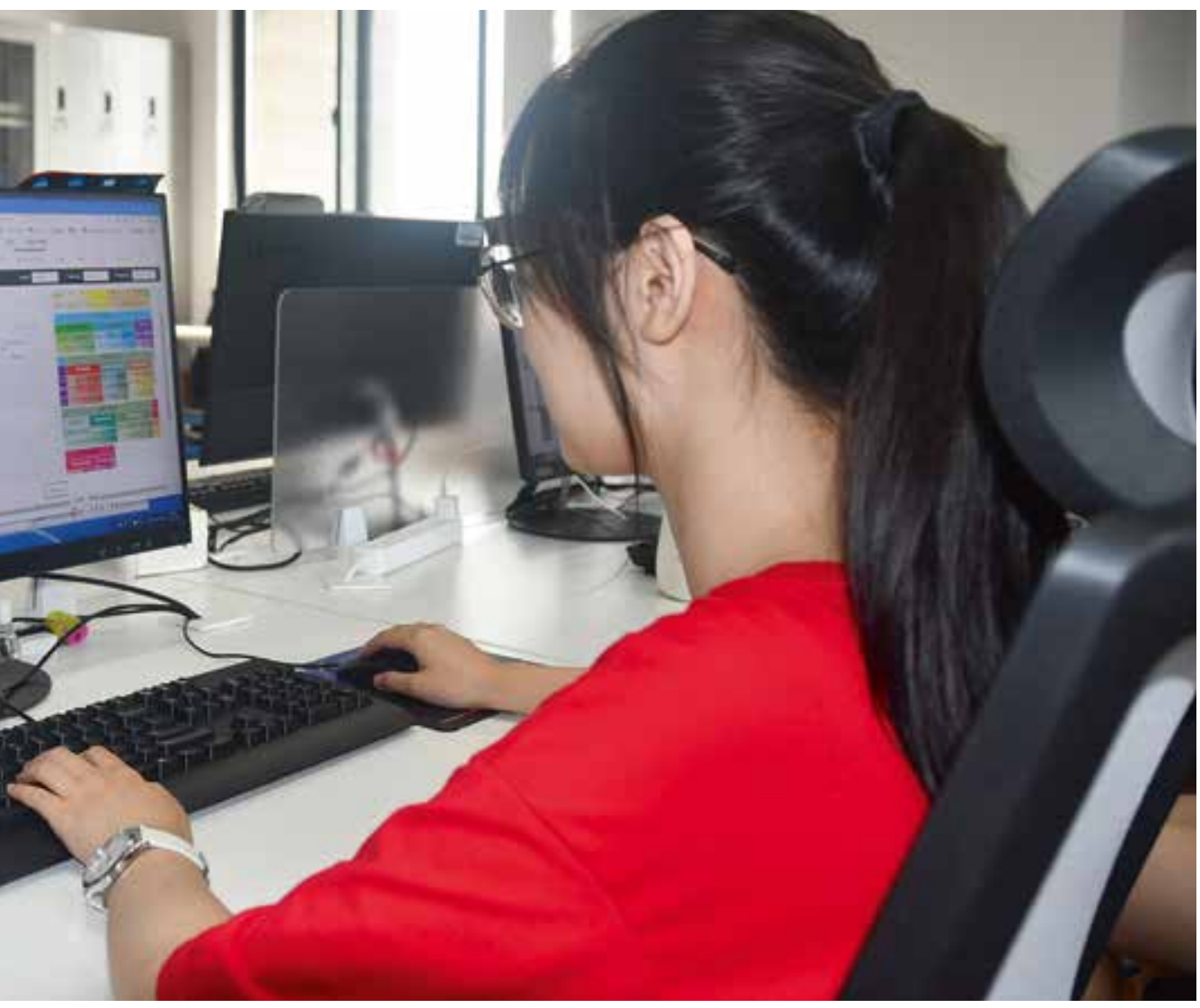

range of geoscience data were not available until now. In this way, DDE may help to solve some of the biggest geoscience questions that remain. The DDE programme is being developed right now, ready for its launch at the International Geological Congress in March next year where geoscientists from all over the world will be able to hear about activities and get involved.

The DEE vision has stimulated large amounts of funding, including $\$ 75$ million from the Government of China to build a DDE-dedicated centre of excellence at Suzhou near Shanghai, with access to one of the world's fastest supercomputers, the Shenwei TaihuLight. In the United States, plans are developing for a DDE centre of excellence looking at geological resources. In Europe, it is hoped that the DDE can be linked with the

'OneGeology' concept (an international initiative of geological surveys working together to make geoscience data web-accessible worldwide).

\section{Building bridges}

DDE will enable the building of bridges between data islands and allow data to be interrogated using modern tools, thereby tackling some of the most important and pressing questions of our time. However, a big part of DDE will also be building communities of like-minded scientists. It could be said that geology has lagged behind other physical sciences in capitalizing on big data-but with DDE, geoscience will catch up. Perhaps some big geological discoveries still lie ahead of us?

Prof Mike Stephenson is President of the Governing Council of DDE, Executive Chief Scientist at the British Geological Survey and Visiting Professor at Nanjing University. Email mhste@bgs.ac.uk

Prof Qiuming Cheng is President of the International Union of Geological Sciences

Prof Chengshan Wang is a member of the Chinese Academy of Sciences and Professor at the China University of Geosciences

Prof Junxuan Fan, is a Professor at the Nanjing University

Prof Roland Oberhänsli is Past-President of the IUGS.

Further information on the Deep Time Digital Earth programme can be found at http://www. ddeworld.org 